\title{
A Case Study Color as a Visual Language: Focused on TV Commercial
}

\author{
Cindy Muljosumarto \\ Desain Komunikasi Visual, Fakultas Seni dan Desain, \\ Universitas Kristen Petra, Surabaya, Indonesia \\ E-mail: cindy.mul@petra.ac.id
}

\begin{abstract}
Color is an important element of a visual design, it also an essential element in a TV Commercial (TVC). This paper examined color as a 'language' to convey the TVC message to the audience, using Kobayashi's Color Image Scale to be the color descriptor combined with psychological colors theory and some data from professionals. To gain more specific result the data also compared with an experimental method that has been done with a group of potential target audience of this product. The last step is an analysis and conclusion. The result will be a new finding about color function in advertising and hopefully could lead into new creative ideas of TVC ads.
\end{abstract}

Keywords: Color, visual language, TV commercial.

\section{Introduction}

A picture could create visual information through a combination of line, shape and color in any media. We use this information using our brain and eyes to interpret the real world (Messaris, 1997). This visual information could affect someone behavior, and color is a part of that visual information. Kareklas et al. (2013) also mentioned that, "Color is a dominant visual feature which can affect consumer perceptions and behavior."

\section{Color in visual communication}

Gorn et al. (1993) mentioned there are basic independent properties of colors according to color theorists. Hue is the pigment of color. Chroma is the richness or deepness of the color (saturation) which highly saturated colors have a greater proportion of color pigment in them. Value is the degree of lightness or darkness of the color relative to a neutral scale, which extends from pure white to pure black. They also stated that color is a visual stimulus. A higher level of chroma (saturation) and value (lightness) influence the feeling of arousal and relaxation respectively (in each specific case). The greater feelings of relaxation that affected by value, appears to favorably influence the brand attitude. On the other hand, chroma affected arousal and makes intuitive sense. The effect of color in ad could suggest the peripheral route to persuasion. According to Sherin (2012), hues and tones could enhance the message while using a repeated color and elements in a design could create a unified look and feel. If we look from the color spectrum, color are associated with two moods: the warm, active and exciting qualities of red and its analogues hues; and the cool, passive and calming qualities of blue, violet and green. The warm color is suitable for an outwardly integrated type of people and cold color is suitable for an inwardly integrated type of people. Therefore the warm color is better to convey pleasant and welcomed feelings, which could be used in the ad message. Color also has psychological effects that influencing feeling and emotion. Felix Deutsch proved that color could make changes in blood pressure, pulse-frequency and rhythm of a person (as cited in Birren, 2013). Through the research consumer in psychological aspect, this knowledge is useful to create an effective message for the target audience.

\section{Visual Language}

As mentioned in Malamed, C. (2011), vision is the dominant sense for acquiring perceptual information. It is easier and faster for brain to collect information through visual experience. Human have a large capacity for picture memory and could remember thousands of images with few errors. We depend on visual language for its efficient and informative value to be able acquiring a lot of information. Although according to Kress and van Leeuwen (2006) (as cited in Botturi, Stubbs, 2008) visual languages are not that transparent and universally understood because they are have a culturally specific meaning. In an interdisciplinary senses, visual language have multiple roles, first is to communicate a message through a visual or functional language, second is, visual language 
could portray a synthetic idea, an image or do a metaphor from a complex idea. Thrid, visual language could produce meanings for its use. (Winograd, 1996; Botturi, 2006; Kress \& van Leeuwen, 2006; as cited in Botturi, Stubbs, 2008). In order to learn about human behavior, thinking process, learning process to do something, we could observing their cultural aspects which influencing each individual human processes. Visual language is used to interpret and simplify the complex compound ideas about culture so it could be easier to understand. Botturi also mentioned that visual language might develop creativity and enhance communication (Botturi, Stubbs, 2008: 53- 131).

\section{TV Commercial}

According to Henrik Dahl (as cited in Messaris, 1997) most of the people are not searching for an advertising intentionally. In a contrary, they are developing more skills these days to avoid ads. The rapid advance of technologies, provide them to choose their own need for information. They could filter what they want to see or not. This phenomenon initiates the advertiser to reverse the trend by using the Internet and other new media (Ali, 2016). According to Ali, to reach and persuade the consumer, a creative ad is necessary to gain their attention. A creative ad should be different and unique but still relevant with the consumer needs. Creative TV ads could effectively create a positive and better ad recall, which can be transferred to the brand. These two aspects are necessary to measure the effectiveness of that ad, whether the audience could respond the ad message or not. Meanwhile the content of the message and the advertising direction should match with the brand needs itself. (p.928 - 929).

An effective method to grab audience attention and willingly to expose themselves toward TV commercial, is through a visual manipulation such as manipulating a symbol to grab audience's attention. According to a psychologist Roger Shepard, an unusual things or different from our expectation could naturally makes our human perceptual system to pay special attention (Messaris, 1997). One of the example is surrealism approach that used in an ads, can make audience to decipher the meaning of the ads. This action means, target audience already involve in the communication process of the ads. Therefore Messaris described that this surrealism approach is suitable for visual advertising to gain audience attention while conveying the ad message.

\section{Color in TV Commercial}

TV commercial is a part of advertising campaign strategy. Which consist of a lot of visual elements such as graphic and color, beside that sounds such as music, dialog, and audio effects. To create a good quality of TVC an expert in each element is needed, because of these reason TVC commercial tends to cost a lot compare to another media.

The important element in video is a visual and an audio which applicable in TV commercial (TVC). Visual elements consist of graphic, motion graphic and color. Color holds an important part in visual composition, because color will control the unity and continuity of the designs. Color also has a role to set the mood or tone for the story. The color usage will be very crucial during the story to let audience understand the message. Because of this fact, there is a professional editor or colorist in every TVC production, and many of them earn the most (Amri and Nicholas, 2013). ${ }^{1}$ The similar opinion about color usage also stated by Hornung, that the color used in print ad advertising is for appealing reason and to help to tell the story (Hornung, 2012: 127).

It is important to create concept before the shooting progress. This concept is depends on the product brand, the message and the target audience. According to Mr. Avissena Amri (TV Commercial Director) usually target audience will be a guidance to determine the TV commercial color mood. For example a children milk product but the target market is their mother, so the color usage doesn't have to be a saturated primary color but desaturated color also could be possible to use. Nowadays the usage of color spectrum already has a lot of variation and this also a common things that we can found in every TV commercial, so audience already get used to it. Even though we could find a stereotype color template for certain product or mood tone, according to Mr. Avissena. For example, to create the girly and cute mood, Japanese or Korean looks, they use mostly pastel color. For the real storytelling they will use earth color, and for modern look they will use cold color. Although it is not a necessary rule to obey, but in advertising some products already have a requirement or a concept for the brand identity so it's quite difficult to do some experimental things with color. ${ }^{2}$

To produce a good and natural color for TV commercial, the shooting progress is the most important things such as surrounding ambience, art properties, wardrobe, lighting (indoor or

\footnotetext{
${ }^{1}$ An interview discussion with professional movie-video art director and TV commercial Director, Mr. Nicholas Nicky and Mr. Avissena Amri.

2 Avissena Amri - TV commercial director
} 
outdoor), filter, background and even the clarity of air. It would be better to create the color during the shooting progress not in the editing (color grading) or post editing progress. ${ }^{3}$ According to Mr. Avissena, people tend to like desaturated color because of their pervious experience and preference with the color in the cinema movie. Another interesting fact is the volume color effect that we can found in the process of making TV commercial. Apparently the settings place, the weather and light are the factors, which can make one commercial looks different than the others. For example, it would produce a different result to shoot in Indonesia and in Korea even though both of them using the same equipment, properties and crew. As Mr. Avissena mentioned in the interview session, the most beautiful picture will be captured in the area, which has good sun position and less polluted air. He also mentioned that this kind of effect might be not going to happen if we use indoor location with artificial lighting.

\section{Related work}

Some paper which discussed similar topic, such as Panigyrakis and Kyrousi (2013) in this paper they reviewing the literature that published since 1985 - 2012 regarding color in advertising and suggest some direction for the future research. According to Panigyrakis and Kyrousi (2013) most of the past research article was anecdotal rather than systematical and empirical but a little progress has been made in this past decade. Most of them are lack of clear directions in their findings and lack of relevant integrated theory. Also it is not easy to establish the causal between color as an independent variable and consumer responses as the dependent variable. There is also some conflicting findings between the extents studies, for example Lichtlé (2009) said preferred colors increase brand memory whereas Meyers-Levy and Peracchio (1995) said black and white ads outperformed colored ads in terms of recall of ad claims and products attitudes when high resources demands and opposite to the low resources demands (as cited in Panigyrakis and Kyrousi, 2013). Another recent paper such as Mazhar Ali (2016) which investigated the advertising effectiveness of creative TV advertisement for high involvement products and resulted that creative Ads are better than control Ads in generating favorable attitude toward ad and high Ad recall, but not effective to persuading customer to buy the product. There is also recent paper $\mathrm{Li}$ (2016) which using multimodal discourse approach to analyze the interpersonal meaning in Coca Cola TV Advertisement

\footnotetext{
${ }^{3}$ Nicholas Nicky - video art and movie director
}

hilltop version. This paper has made an attempt to investigate the interpersonal meaning is representated and communicated through multi modes such as image (color, prespective, distance), movement (gaze, gesture, facial ex-pression) and sound (speech, music, accented syllables, sonic interaction, rhythm group) in coca cola hilltop jingle. The result, these multiple semiotic modes generate and communicate the interpersonal meaning that enacted between the depicted participants and the audience.

\section{Research Objective}

This research objective is to determine that color could be a 'language' to convey the TVC message to the audience, using Kobayashi's Color Image Scale to be the color descriptor combined with psychological colors theory and some data from professionals. To gain more specific result the data also compared with an experimental method that has been done on potential target audiences. This study will analyze the audience respond between the color TV commercial and black and white version. The last step is an analysis and conclusion. The result will be a hypothesis that color could be a language for TVC, which mean to search a possibility of using only color element to deliver the message. Hopefully the end result will be a new finding about color function in TV commercial and could lead to build fresh and new creative ideas.

\section{Method}

This research used Kobayashi's Color Image Scale to understand how color combination can affect people felling and their psychological emotions. In this color chart, Kobayashi manage to describe people emotions in 180 words, which correlated with the color combination. Kobayashi research methodology and practical application guidelines have been widely accepted and used by major industries in many Asian and Europe countries and suggest over 1.000 associated color combination that can be applied in fashion, interior design, product design and visual media industries (Yoon et al., 2009). The selection of the TVC is based on the objective of this research which to determine color as a visual language to convey the ads message and IKEA's 'Bright, shiny colors' TVC is using colors as its main story and message. IKEA is a home furnishing company that brought its Scandinavian design to Britain and opened their first store in Manchester in 1987 (Baker, R., 2014, November 03, Ikea: a history in ads). Nowadays, IKEA stores are widespread known in the world including in Asia. IKEA launch the 'Bright, shiny colors' campaign coincides with the 
launch of their 2013 IKEA Catalogue in the UK and Ireland on September 8, during the 'X-Factor' on ITV1. Three version durations of the TVC have been produced including 60 " and 30" that run until October 7 (IKEA Inspires with 'Bright, Shiny Colours' | LBBOnline. n.d.), but also can be accessed through the Internet and YouTube. Mother an advertising agency based in London creates the 'Bright Shiny Colours' TVC.

These results are later to be compared with the experimental research using experimental research on a group of people. Paningyrakis and Kyrousi (2013) suggested that experimental research is effectively capturing the impact as consumer response of color in advertising context. Therefore, this research also using the experimenttal research to gain more specific data. The selected TVC was presented to a group of people that consist of 16 potential participants that never saw this TVC before. This group was selected through a different background of nationality, education, occupation, gender and age, but still considered as the target audience of this product. The selection based on the assumption that this TVC might be accessed worldwide through the Internet. This TV commercial will be shown to the group in three stages.

\section{Analysis using Kobayashi's Color Image Scale}

The TVC tells a story of a woman who goes on a magical journey through the new IKEA Catalogue. At first the woman house was seen as white and beige.
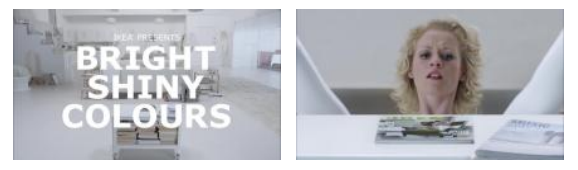

Source: YouTube.com

Picture 1. First scenes

After that she steps through the catalogue into the IKEA showcase that full of inspiring design items and furnitures.

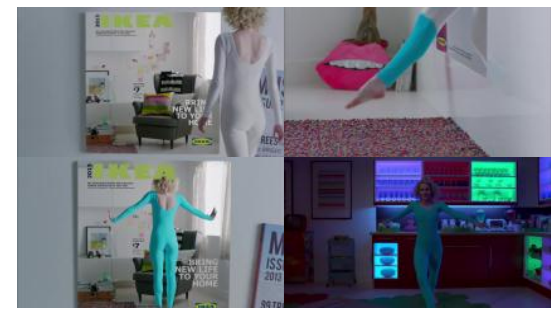

Source: YouTube.com

Picture 2. IKEA TVC scenes
She ends her journey when she emerges from the other side of the catalogue and brings out the inspiration to transform her home.

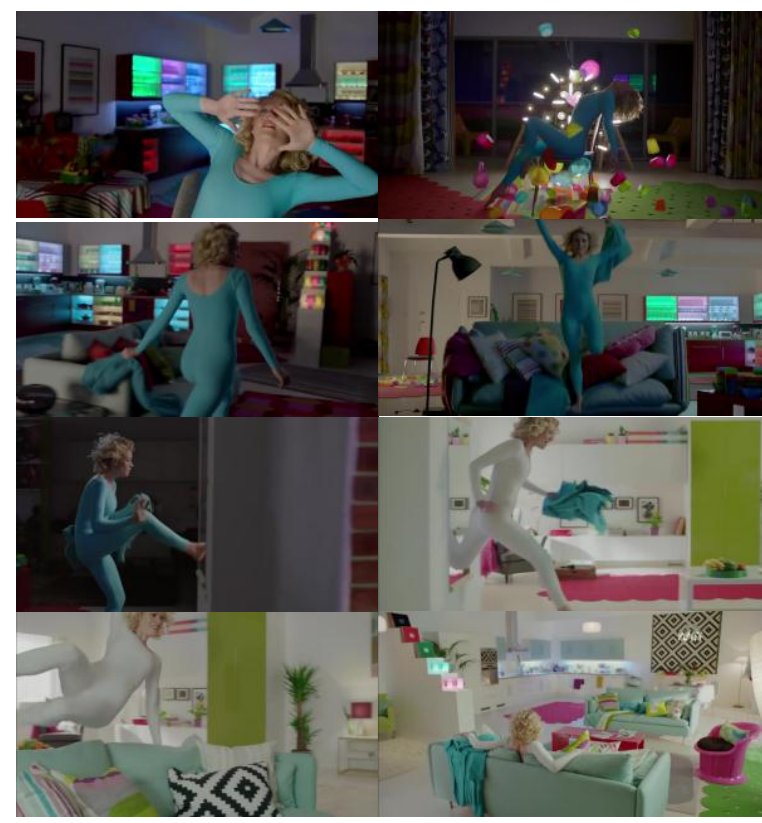

Source: YouTube.com

Picture 3. IKEA TVC scenes

To conduct the analysis some scenes are collected to create the color palette and later be described using color combination image scale and key word image scale on the Kobayashi's Color Image Scale.

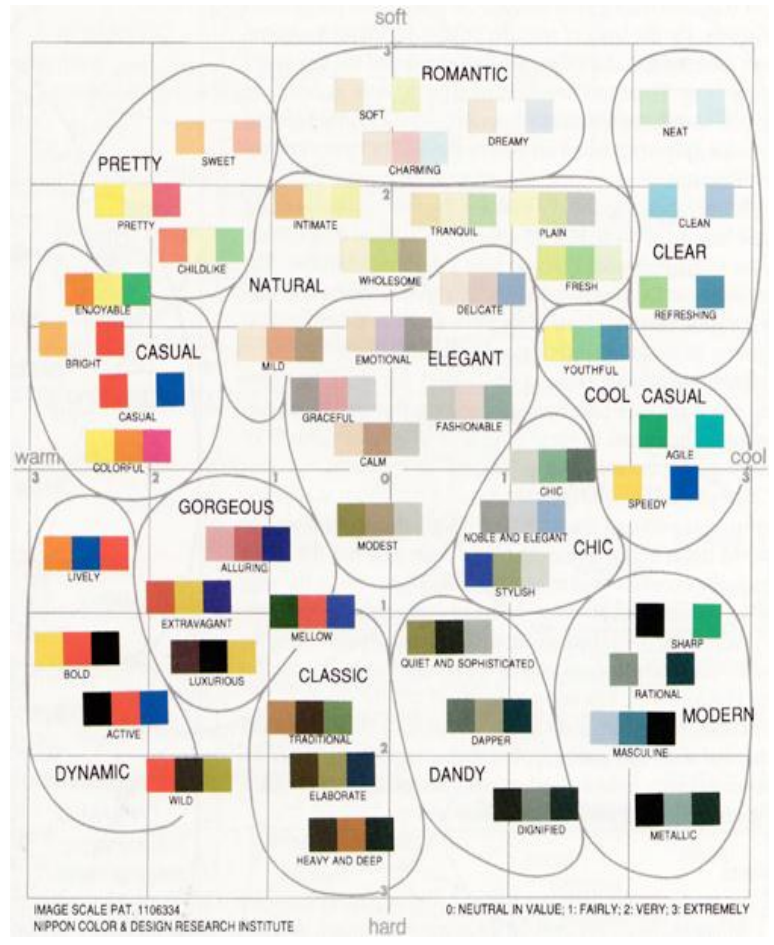

Source: https://s-media-cache-ak0.pinimg.com/564x/2a/87/ 55/2a8755f84e4b1075cd34a1823d3114d6.jpg

Picture 4. Color combination image scale 


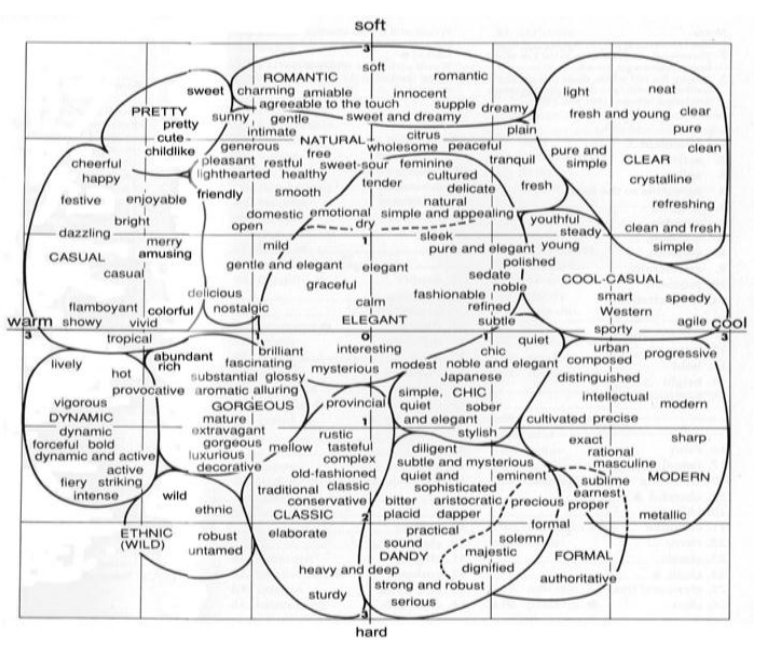

Source: http://thelandofcolor.com/wp-content/uploads/ 2010/12/Color-Image-Scale-final-flat.jpg

Picture 5. Key word image scale

The Kobayashi's Color Image Scale has matched 130 basic colors and 1170 three-color combinations to 180 keyword or image words that related to the ways in which people perceive colors. These 130 basic colors are defined in the Hue and Tone system. (Kobayashi, 1996; Solli and Lenz, 2010). ImageJ program with color inspector 3D plugin was used to generate the color palette and to get more specific result. This plugin shows the color distribution within a 3D-color-space that suitable for video analysis. This plugin could extract the most dominant colors of the scenes. To produce the color palette, the scenes are divided by the storyline sequence. Then using the histogram display mode with the minimum number of color cells to generate more concentrated color distribution in the frames.

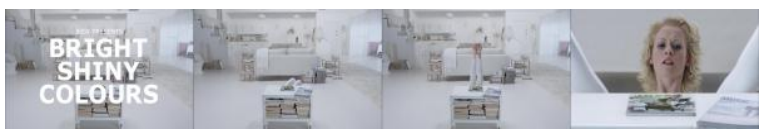

Source: YouTube.com

Picture 6. Beginning part of the story sequences

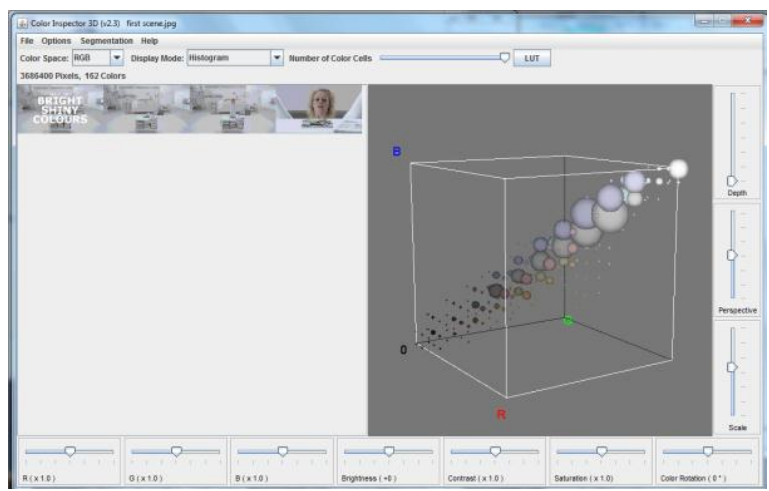

Source: Private documentation

Picture 7. ImageJ 3D inspector analysis result

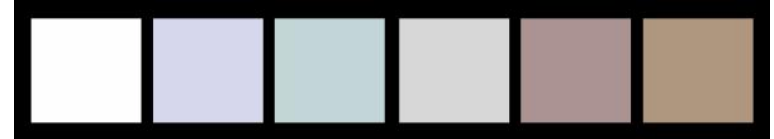

Source: Private documentation

Picture 8. Beginning part of the story sequence color palette

After reading the color palette result with Kobayashi's color combination image scale, I got soft, mild, calm, modest, neat and clean as the words to describe the beginning part of the story sequences. These words are matches with the mood and tone of the story.

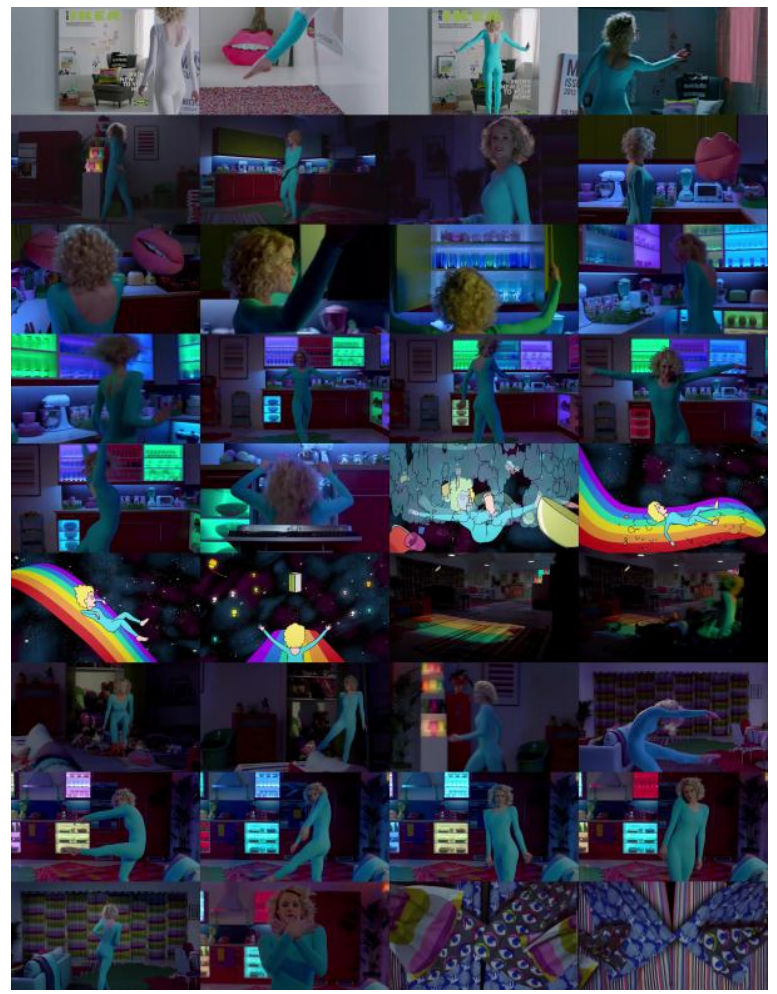

Source: Private documentation

Picture 9. Middle part of the story sequences

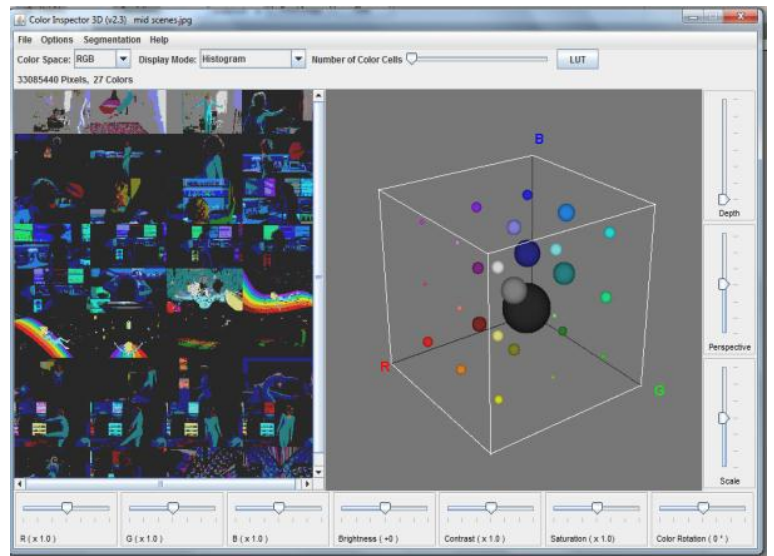

Source: Private documentation

Picture 10. ImageJ 3D inspector analysis result 


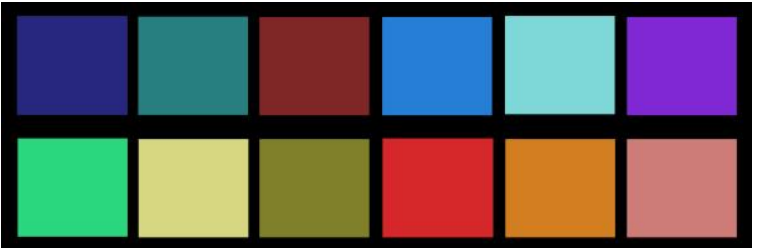

Source: Private documentation

Picture 11. Middle part story sequence color palette

The words that describe the middle part of story sequences based on the color palette result are, enjoyable, bright, colorful, lively, fresh and agile. As we can see in this middle part of the story, the scenes sequence becomes colorful and lively. The described words are matched with the storyline.

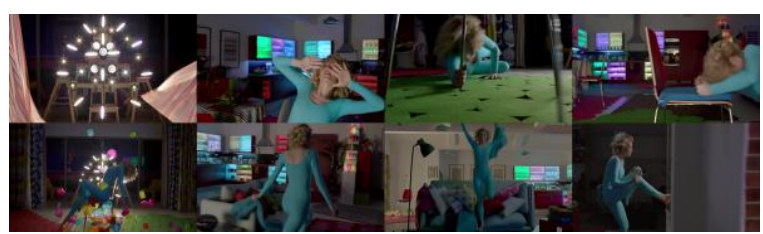

Source: Private documentation

Picture 12. Climax part of the story sequences

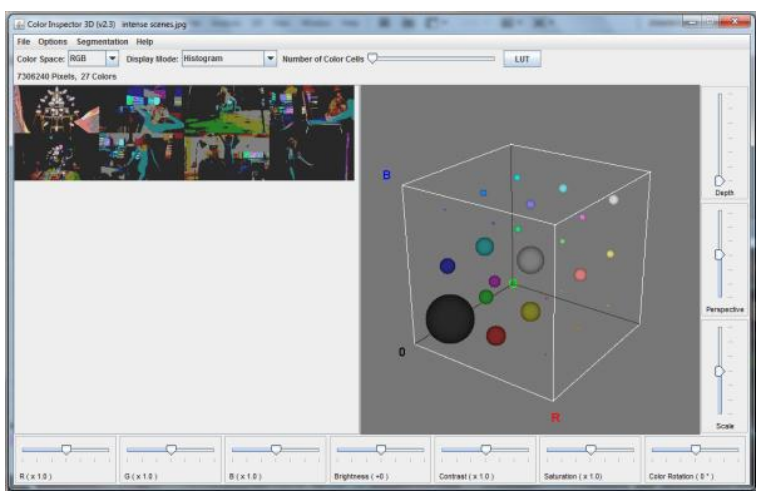

Source: Private documentation

Picture 13. ImageJ 3D inspector analysis result

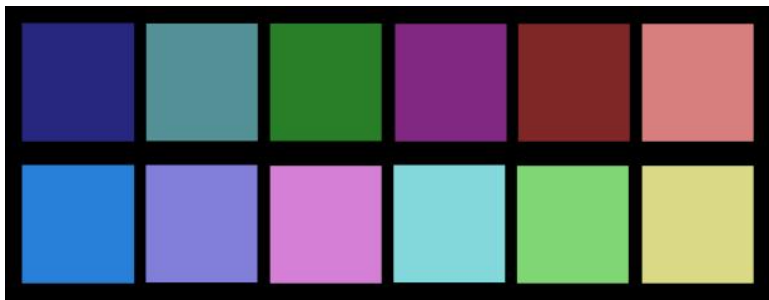

Source: Private documentation

Picture 14. Middle part story sequence color palette

Through this color palette I found the same words as the previous scenes such as, agile, fresh, lively and colorful. The adding words that describes in this sequence are alluring, extravagant, youthful and stylish. I also found out that the later words are suitable to enhance the mood in the climax part of the story.

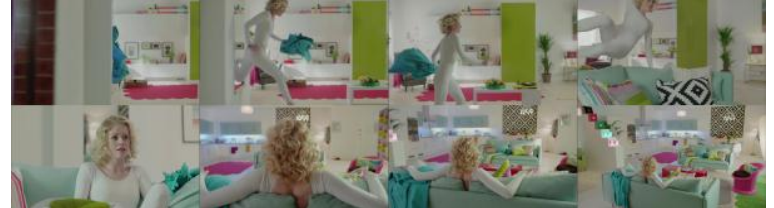

Source: Private documentation

Picture 15. End part of the story sequences

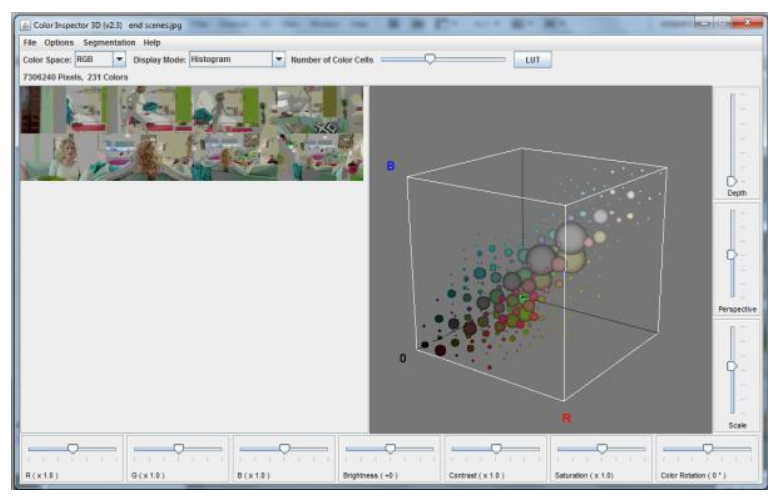

Source: Private documentation

Picture 16. ImageJ 3D inspector analysis result

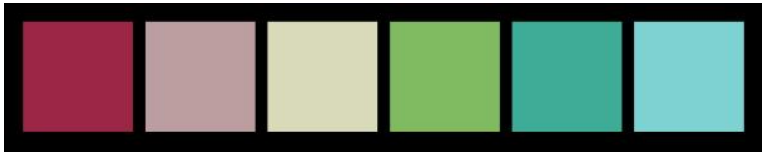

Source: Private documentation

Picture 17. End part story sequence color palette

From the last sequences the words that I got are casual and fresh, to describe the scenes.

Through this result, the most prominent (emotions) key words that had been found in this TVC are colorful, fresh, extravagant, youthful, lively, enjoyable and casual. This result will be matched with the experimental result.

\section{Experimental Analysis}

This experimental analysis was conducted by observing the participant reaction through the various elements in this TVC such as, sound, image and color. But, still focused on the color as the main argument of this research. The aim of this experiment is to understand the participant perception of emotion in this TVC.

There are three stages to examine the participant reaction for this TVC. First, they would saw the TV commercial only in black and white video without the sound. This stage aim is to found out about the participant comprehension on the TVC through the color information only. Which in this stage it will only display in the black and white color. Therefore, the sound was removed to make the participant focused on the images instead. 


\section{Stage 1. Black and white video without sound}

The first analysis is to find out the participant comprehension about this video without revealing any information beforehand.

Table 1. Participant comprehension

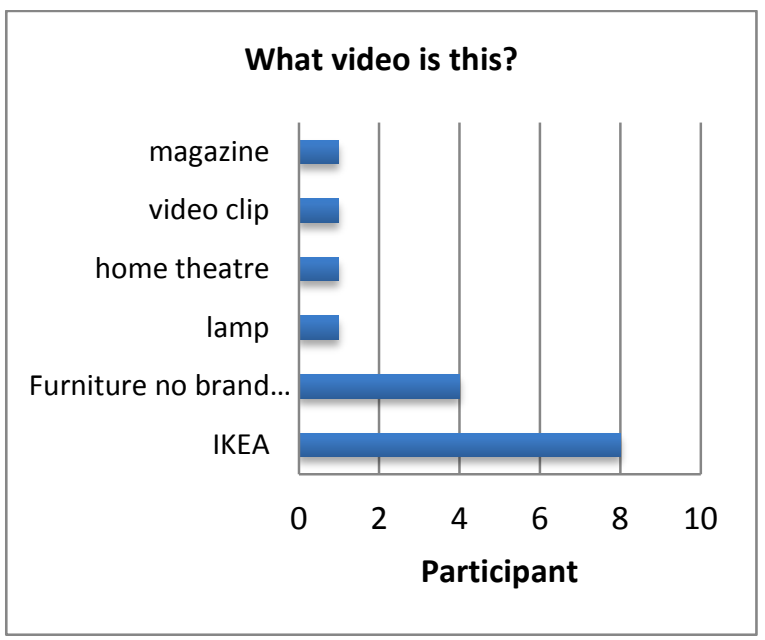

On this first stage, most of the participants know what kind of video and the product, but some of them still didn't know what kind of brand it is. This result occurred because of the lack information in the visual. Without the color information, the IKEA logo on the magazine was blended with the surrounding colors and easily missed. Meanwhile, for the rest mislead answer was caused by the lack of the brand experience and information about this product. Therefore is hard for them to be aware of this brand.

The next question is about the emotion that they feel after watching this video. The result most of the participant came out with negative emotion such as boring and confused and lead them to curiosity about this video instead of the product itself. There are also some participant who feel this video is boring and not interesting, these emotions occurred because the lack information of color and sound. Despite the majority answer, there are also some participants who feel the positive feeling such as, enjoyable, amazed, happy, fun and lively. They ignored the lack of information in color and sound and just focused on the image or the visual movement.

\section{Stage 2. Colored video without sound}

In this stage, participant watched the same video with color element but still without the sound. The aim of this stage is to find the difference of the participant reaction from the previous stage and to find new perception from them with color as the additional visual element.
Table 2. Participant comprehension

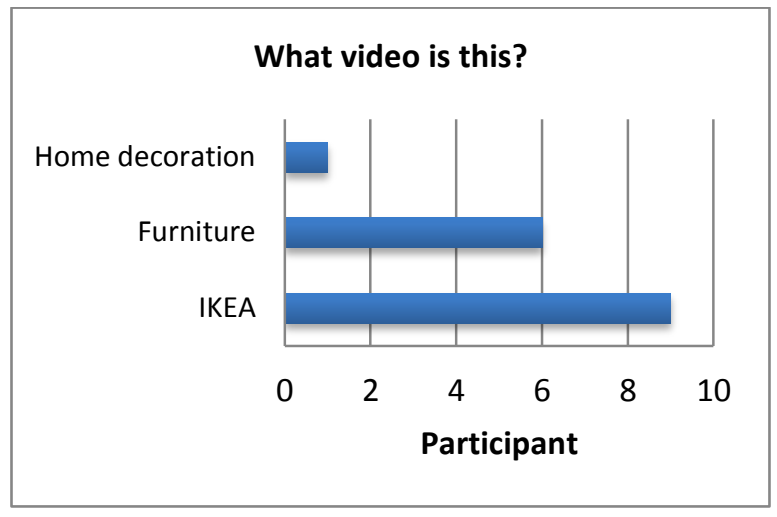

Through this stage, all participants already can distinguish that this is a TV commercial. They also could distinguish the product on this video compare to the previous stages. Although some of them not mentioning the brand name, but all of them could mention the same category product. Most of them said that they gain more information through the color.

In this stage, all of the participant feel the same positive emotions toward the video. Most of them describe the emotion of this TVC are: happy, interesting because of the color combination, attractive, fun and comfortable. This stage proved that the color addition in this TVC could enhance the TVC message and lead the audience into the expected mood.

\section{Stage 3. Colored video with sound}

In this stage the entire participant already understand this TVC message and they could recall the brand already. Most of them described the same emotions that occurred in this TVC, such as, happy, enjoyable, cheerful, interesting, likeable and comfortable. Most of them choose the last stage as the clearest stage to reveal the TVC message, because the sound element was presented and enhance the message. But some of them already knew the message at the second stage which color was presented in the video. They said the color addition help them to understand this TVC better. Meanwhile, six participants said they already knew the message since the first stage because their knowledge of the brand.

\section{Compared Analysis Results}

From the Kobayashi's method, I managed to describe the image words through the color, which are: colorful, fresh, extravagant, youthful, lively, enjoyable and casual. Afterward, from the experimental research I summarized the participant description for the emotions in this TVC, such as, 
happy, enjoyable, cheerful, interesting, likeable and comfortable. Using the Kobayashi's color combination image scale I found out that the key words are in the same area and matched with the color palette results.

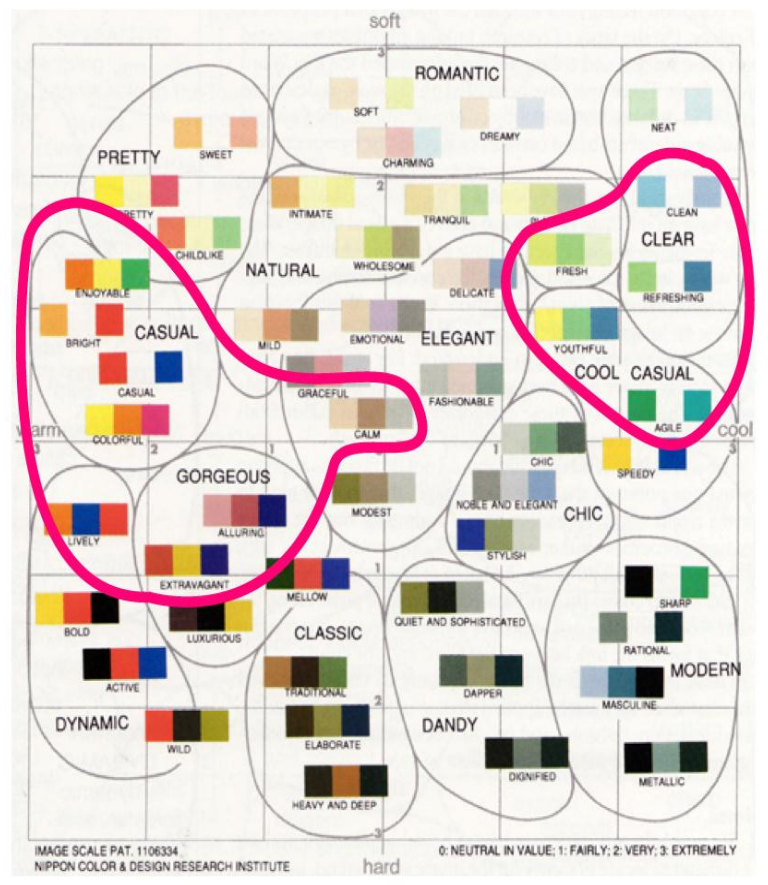

Source: Private documentation

Picture 18. Result scale

\section{Conclusion}

To produce an effective TV commercial a strong concept will be needed, but this concept has to be done with the good support from visual and audio elements. Although through this experiment some participant could understand the message only with black and white image, but most of them agrees that color image will enhance the product information and will deliver the message better than the black and white image. The reason is, in this experimental the black and white video actually not really portrayed as a non-colored video because it still has the value and contrast which help to distinguish the image. In another case, this study proofed that color is an important element to communicate the TV commercial message and it could be a visual language of TV commercial. According to Sherin (2012), color is one of the most powerful tools for designer to communicate the client's message. It can convey the idea, the meaning, show or emphasis the emotions and has cultural relevancy. The similar argument also stated by Goncu-Berk (as cited in DeLong and Marinson, 2012) that color can convey many meanings and message at a time and reduce the span of time to comprehend the message.
Through this research, I found that color could be a visual language that contributes to convey an idea or message in an ads, in this case is in TV Commercial. Another founding is that we can measure or describe the color image word and found out the emotion or feeling that associate with it using the Kobayashi's Image Color Scale. With this information designer could create more creative ads with an effective message using the appropriate color combination. Still according to Sherin (2012), a successful color relationship, not only to catch and hold viewer's attentions but it can also determine the consumer to buy or consume the product. Therefore, the perfect color combinations can be used to effectively communicate information. In fact, if it used effectively color will communicate the content and ideas quickly without overwhelm the viewer's attention span. The same argument also mentioned in Chattopadhyay and Yi (1993), that color could have influence towards the ads message which also relate to brand attitude. Creating a pleasant color combination that called harmony is important, because it has more to do with achieving the intended reaction from audience. Just like in this IKEA's TVC, the color harmony are helping the audience to understand the visual message.

These uses of color is not only related with composition in graphic design but also more complex consideration that require another aspect of visual literacy from the designer. Such as how messages are encoded and decoded by particular audience with various background, education, culture and age (Sherin, 2012). Therefore, this research result is not absolute. Another reason is because the result will be different and vary for another TVC depends the message and the concept.

\section{Research Limitation}

This research was done with limited time and the academic ability of the author to do the detail experiment. It would be very recommended to do a full and detail experiment with better method and add more variant sample not only for TVC, for the future study research.

\section{References}

Ali, M. (n.d.). Evaluating Advertising Effectiveness of Creative Television Advertisements for High Involvement Products. SSRN Electronic Journal. doi:10.2139/ssrn.2752965

Gorn, G. J., Chattopadhyay, A., \& Yi, T. (1993). Color in Advertising. SSRN Electronic Journal. doi:10.2139/ssrn.2179429 
Kareklas, I., Brunel, F. F., \& Coulter, R. A. (2014). Judgment is not color blind: The impact of automatic color preference on product and advertising preferences. Journal of Consumer Psychology, 24(1), 87-95. doi:10.1016/j.jcps. 2013.09.005

Li, D. (2016). Multimodal Discourse Analysis of the Interpersonal Meaning of TV Advertisements. International Journal of Social Science and Humanity,6(12), 934-938. doi: 10.18178/ ijssh.2016.v6.776

Messaris, P. (1997). Visual persuasion: the role of images in advertising.

Panigyrakis, G. G., \& Kyrousi, A. G. (2015). Color effects in print advertising: a research update (1985-2012). Corporate Communications: An International Journal, 20(3), 233-255. doi: 10.1108/ccij-12-2011-0072

Yeon, Y. S., Tofle, R., Schwarz, B., Oprean, D., \& Young, C. J. (2009). Understanding the Meaning of Color Environments: A Virtual Environment Exploratory Study. IDEC Proceeding, 2009 Annual Conference, 924-934.
Botturi, L., \& Stubbs, S. T. (2008). Handbook of visual languages for instructional design: theories and practices. Hershey, PA: Information Science Reference.

DeLong, M. R., \& Martinson, B. (2012). Color and design. London: Berg.

Faber, B. (2013). Color Psychology and color therapy. Mansfield Centre, USA: Martino Publishing.

Hornung, D. (2012). Colour a workshop for artists and designers (2nd ed.). London, England: Laurence King Publishing.

Kobayashi, S. (1991). Color image scale. Tokyo: Kosdansha International.

Malamed, C. (2011). Visual language for designers: principles for creating graphics that people understand. Beverly, MA: Rockport .

Sherin, A. (2012). Design elements, color fundamentals: a graphic style manual for understanding how color impacts design. Beverly, MA: Rockport .

Vera, N., M. Si. (2014). Semiotika dalam Riset Komunikasi. Bogor, Indonesia: Ghalia Indonesia. 